\title{
EFFECT OF SULFATES IN THE DIET OF PREGNANT EWES ON PLASMA CONCENTRATIONS OF COPPER AND CERULOPLASMIN IN NEWBORN LAMBS
}

\author{
M. Mohebbi-Fani ${ }^{1}$, K. Mostaghni ${ }^{2}$ \\ ${ }^{1}$ Department of Animal Health and Nutrition, School of Veterinary Medicine, Shiraz University, \\ Shiraz 71345-1731, Iran, E-mail: mohebbi@hafez.shirazu.ac.ir \\ ${ }^{2}$ Department of Clinical Studies, School of Veterinary Medicine, Shiraz University, Shiraz 71345-1731, Iran
}

The effect of short-term experimentally elevated dietary sulfates on copper status of heavy pregnant ewes and their newborn lambs was studied. Sixteen pregnant Mehraban ewes, 4-4.5 years old, were fed a basal diet containing $0.19 \%$ sulfur, 8 PPM copper and 3.9 PPM molybdenum from about the 100th day of pregnancy till 3 days postpartum. During the last 25 days of pregnancy, the animals were fed individually and 10 ewes (the experiment group) received $0.38 \%$ extra sulfur as sulfate daily in their diet. Liver copper concentration of ewes was determined at about the 100th day of pregnancy and on the 3rd day postpartum. Plasma concentrations of copper and ceruloplasmin were measured weekly before parturition and also at the 1 st hour and on the 3rd day after lambing. Concentrations of copper and ceruloplasmin were also measured in plasma of newborn lambs at the 1st hour (before sucking colostrum) and again on the 3rd day after birth.

In ewes of the control group, liver copper concentration increased significantly $(p<0.05)$ during the experiment. This increase could be due to removal of animals from pasture and feeding them with a controlled diet. In the experiment group, however, a slight and nonsignificant decrease in liver copper concentration was observed $(\mathrm{p}>0.05)$, which could be due to increased requirements during heavy pregnancy together with the effect of sulfates in reducing the availability of dietary copper. This decline, however, was not sufficient to produce even marginal deficiency. No significant difference was observed in plasma concentrations of copper and ceruloplasmin between the two groups. In newborn lambs, plasma concentrations of both copper and ceruloplasmin were similar at birth. On the 3rd day, however, plasma copper was significantly lower in the lambs of the experiment group $(\mathrm{p}<0.05)$. This may be related to the lower concentration of ceruloplasmin in their blood.

It is concluded that sulfates, in short terms, may not result in copper deficiency in pregnant ewes, but may affect copper metabolism in newborn lambs. Routine experiments conducted on adults to detect copper deficiency seem not to be proper for predicting these changes in newborn lambs.

\section{ORAL GLYCEROL AS A GLUCONEOGENIC PRECURSOR IN THE TREATMENT OF KETOSIS AND FATTY LIVER}

\author{
Jesse P. Goff and Ronald.L. Horst
}

National Animal Disease Center, USDA-Agricultural Research Service, Ames, IA 50010

\section{Introduction}

Glycerol can be converted to glucose in the liver of cattle. Glycerol enters the gluconeogenic path- 
way at the level of dihydroxyacetone phosphate and 3-phosphoglyceraldehyde. This is several biochemical steps closer to glucose than the traditional gluconeogenic precursors, propionate and propylene glycol. Use of glycerol as an aid in the treatment of ketosis was suggested during the 1960 's but not adopted due to high costs. However, newer methods for its production may have removed this barrier. In this study we examined the effect of glycerol administration on blood glucose and did a dose titration to find the toxic dose of glycerol as well in dry cows.

\section{Materials and Methods}

Part 1a. Treatment groups consisted of 3 cows (one of which had a rumen fistula) which were given 1,2 or $3 \mathrm{~L}$ of glycerol in $9.5 \mathrm{~L}$ of water via esophageal pump. Blood samples were taken hourly for the next $8 \mathrm{hrs}$ and also at $24 \mathrm{hrs}$.

1b. Cows were given 1.5 L glycerol in either 9.5 or $37 \mathrm{~L}$ water and blood samples were obtained as described.

Part 2: The $1 \mathrm{~L}$ dose of glycerol was applied to two lactating cows with clinical ketosis. These cows had been previously treated for 2 or $3 \mathrm{~d}$ with IV glucose with little response suggesting fatty liver involvement.

\section{Results of titration study}

1a. At $0.5 \mathrm{hr}$ after treatment mean blood glucose increased 16,20 , and $25 \%$ respectively over pretreatment values at the 1, 2 and $3 \mathrm{~L}$ doses of glycerol. They remained elevated for the next $8 \mathrm{hrs}$. All cows had returned to baseline glucose values at 24 hrs. Two of three cows given the 3 liter glycerol dose exhibited staggering and depression which they recovered from within 4 hrs. Rumen $\mathrm{pH}$ was unaffected by treatment with glycerol. Diuresis was observed in all cows given the 2 and $3 \mathrm{~L}$ doses of glycerol.

1b. Diluting the glycerol in a larger volume of water had only a small negative effect on the increase in blood glucose concentration achieved with the less diluted glycerol. However blood glycerol concentrations were significantly reduced by administration in a larger volume of water.

\section{Results of glycerol application to ketotic cows}

In both cases ketone level in urine was reduced to trace amounts and milk production increased. In the first cow blood glucose increased from $48 \mathrm{mg} / \mathrm{dl}$ prior to treatment to $75 \mathrm{mg} / \mathrm{dl} 0.5 \mathrm{hr}$ after treatment and was $109 \mathrm{mg} / \mathrm{dl} 5 \mathrm{hr}$ after treatment. In the second cow the blood glucose did not increase until about $4 \mathrm{hr}$ after treatment when it increased from $48 \mathrm{mg} / \mathrm{dl}$ to $74 \mathrm{mg} / \mathrm{dl}$ and was just $64 \mathrm{mg} / \mathrm{dl}$ $8 \mathrm{hr}$ after treatment.

\section{Conclusions}

Glycerol offers another means of treating cows for ketosis which may have less toxic effects than a similar amount of propylene glycol. The toxicity seems to be due to high blood concentration of glycerol which has a hyperosmotic effect within the brain according to human medical studies. Administration of glycerol in larger volumes of water can make this treatment much safer while retaining most of the benefits. 